the all too short notice he gives of the ethnography of the country is concerned with this question. Space only allows of the conclusions at which he arrives being given.

After noting the greater density of the population in the southern part of the colony, a result partly of the forcing seawards of the people by repeated migrations from the north, and partly of the exceptional fertility of the ground; he sums up rather unexpectedly for the remainder of the colony by saying, " tandis que les grandes rivières de l'intérieur font l'office de pôles répulsifs de la population, les montaynes ont été au contraire des pôles attractifs."

The book is essentially one for the geologist, and, if in some places the amount of detail given appears almost too great, we have in M. Hubert's work a most comprehensive and valuable description of an important West Coast colony.

In view of what $M$. Hubert has been able to do for Dahomey, and Drs. Esch, Solger, and others for Kamerun, it is somewhat dispiriting to find a less keen interest taken by geologists in England in regard to the investigation of the not insignificant British colonies and dependencies.

J. P.

\section{THE SOLAR SYSTEM}

The Solar System. A Study of Recent Observations. By Charles Lane Poor. Pp. $\mathrm{x}+3$ ro; illustrated. (Lundon: John Murray, I908.) Price 6s, net.

$\mathrm{N}$ putting into book form his lectures at the Colum1 bia University, Prof. Poor has rendered a great service to those serious students who, unequipped with a technical vocabulary and a knowledge of mathematics, yet desire to become acquainted with our present-day knowledge of the solar system.

The book is distinctly different from the majority of astronomical text-books in respect to the relative importance attached to the various parts of the subject. Prof. Poor's lectures were evidently intended to supplement the available text-books, and difficult matters, generally given but brief notice, are treated more fully and so clearly that the general reader will find them now well within his limits. This characteristic of the book is noticeable from the beginning, where the author discusses the moon and the alleged variations of lunar features, the earth as an astronomical body, and the tides. The figure and mass of the earth, and their determination, the variation of gravity with latitude, the modifications undergone by the luni-solar tide ere it produces the effects seen round various coasts, and similar subjects are treated comparatively fully.

In the descriptions of the various attempts to measure the solar parallax (chapter iv.), the author refers to the 1900 observations of Eros as likely to afford trustworthy values, but dnes not appear to have included the preliminary results which have accrued from the Greenwich and Cambridge campaigns.

The chapter on the physical characteristics of the sun is more conventional in its treatment, the history, nature, and changes of sun-spots being discussed at some length. A striking illustration of the variation with latitude of the solar rotation is provided in the brief description of the relative displacement of landmasses which would follow did the earth but exhibit the same mobility; in a few days from the commencement of a rotation, South America would have displaced South Africa, whilst Sumatra would be directly south of New York. The explanation of the LockyerJanssen method of observing solar prominences leads up to the more recent photographic application of the principle in the spectroheliograph, and several of the Yerkes results are reproduced.

The brief descriptions of the instruments and methods whereby the sun's light and heat have been determined are especially clear, and should give every reader a very fair idea of the results achieved by the beautiful researches of Pouillet, Crova, Violle, Langley, and Abbot.

In the succeeding chapters the planets are discussed, first generally, as to their apparent motions, mutual attractions, \&c., then seriatim. The relative certainty with which their various markings have been established is treated at some length, and some of the conclusions arrived at by Prof. Lowell come in for sharp criticism. But it must here be remarked that that observer has himself stated that the Venus markings are not so hard or regular, or so Martian in their appearance, as they were at first reported to be, whilst many of the theoretical arguments against, and practical negations of, the presence of water vapour in the Martian atmosphere will avail little against the spectroscopic evidence obtained at the Lowell Observatory by Mr. Slipher (see Nature, No. 2002, March 12, p. 442) since this book was written.

The present-day rapid march of astronomical discovery is further illustrated in the chapter (xii.) on satellite systems, in which the author recounts the discoveries of three new satellites in as many years; yet the tale is incomplete, for, naturally, $J$ viii is not in the list. After a chapter on comets and meteors, the book fittingly concludes with one on the evolution of the solar system, in which the author, after taking a brief historical survey of the various hypotheses, shows how the planetesimal-spiral hypothesis of Chamberlin and Moulton may be held to explain most satisfactorily the many, and sometimes apparently inconsistent, phenomena observed.

The volume is beautifully printed and illustrated, whilst its freedom from slips shows that the author has exercised the same minute care over the proofs that he has in the selection and exposition of the matter. William E. Rolston.

\section{OUR BOOK SHELF.}

Handbuch der Pharmakognosie. By Prof. A. Tschirch. Part i. (Leipzig: Chr. Herm. Tauchnitz, rgo8.) To be completéd in about 30 parts at 2 marks (2s.) each.

During the past twenty-five years there has been no lack, in Europe or in the United States, of textbooks of pharmacognosy, most of which have been designed to meet the requirements of limited circles of students, and have doubtless more or less efli. ciently served their purpose. But Prof. Tschirch 